\title{
Mechanical Properties of Tire-Rubber Particles Contained Mortar Composites
}

\author{
Deok-hwa Jeong*, Jung-ho Cho, Seung-yeon Choo and Choon-Wook Park \\ School of Architecture, Kyungpook National University, 80, Daehak-ro, Buk-gu Daegu, Korea, 41566 \\ ${ }^{*}$ Corresponding author
}

\begin{abstract}
In the present study, a preliminary experimental work was carried out to examine the effect of mixing waste tire-rubber particles with cement mortar to develop an impact resistant and sound-reducing mortar composite. Laboratory tests were conducted to determine compressive and flexural strengths for six different waste tire-rubber particle contents as a replacement for an equal part of sand in mortar by volume. Experimental results showed that $5 \%$ replacement of sand with tire-rubber particles showed the highest compressive and flexural strengths.
\end{abstract}

Keywords-mortar, waster-tire rubber, mechanical property, air content, absorption

\section{INTRODUCTION}

With the rapidly growing number of vehicles in South Korea, the disposal or treatment of waste tires from vehicles is a growing big environmental concern due to the difficulty of finding disposal sites for simple dumping. The recovery of energy and materials from waste tires is important. Around the world it is estimated that 13.5 million tones of tires are scrapped every year. These numbers include all sorts of tires from car tires to truck tires and the huge tractor and earth moving tires. There are now a variety of technical solutions to the problem of recovering waste tire-rubbers, and tire industry is finding an increasing number of applications for its use [13].

The common applications of waste tires in civil industry are subgrade fill, backfill for walls, subgrade insulation for roads and playground surface material. Therefore, the necessity to find more alternative applications to use waste tires is recommended in terms of effective waste tire-rubber applications. One of the recommended applications of waste tire rubber is a potential use in the concrete industry. Over the past few years, a number of researches have been conducted on the use of different shapes and sizes of waste tires in concrete for improving concrete properties, such as strength, damping, ductility and durability [4-7].

The research of cementitious composite containing waste tire-rubber particles has not been widely investigated, the use of waste tire-rubber as a replacement of sand gradually increased around the worlds. The objective of this study is to investigate the mechanical properties of tire-rubber particle cement mortar (TRPCM) as a preliminary work in developing an impact sound reducing concrete using waste tire-rubber particles. In this work, compressive and flexural strength are also examined.

\section{EXPERIMENTAL PROGRAM}

In order to investigate mechanical properties of tire-rubberparticle cement mortar (TRPCM), a total of six mixtures including a control mix were cast through this work. For each mixture, 9 cube specimens of $50 \times 50 \times 50 \mathrm{~mm}$ for compressive strength test and 9 beam specimens of $40 \times 40 \times 160 \mathrm{~mm}$ for flexural strength test were fabricated.

\section{A. Materials}

The materials used in the tire-rubber-particle cement mortar (TRPCM) were fine aggregate (sand), waste tire-rubber particles and cement. The cement used in the study was type I/II Portland cement which produced according to the Korean standards KSL5201. The specific gravity and specific surface area of the cement were 3.15 and $3,548 \mathrm{~cm}^{2} / \mathrm{g}$, respectively. Natural sand having a maximum particle size of $4 \mathrm{~mm}$, specific gravity of 2.50 and fineness modulus of 2.42 was used. The waste tire-rubber-particles as replacement of fine aggregate (sand) in this study were obtained from mechanical shredding of automobile tires. The average particle size and specific gravity of tire-rubber particle were $1.0 \mathrm{~mm}$ and 0.83 , respectively. The gradation of tire-rubber particles was determined based on the KS F 2502 method. The specific gravity of the rubber-particle was calculated to be 2.77 in this study. The gradation curve of rubber particle is shown in Figure I.

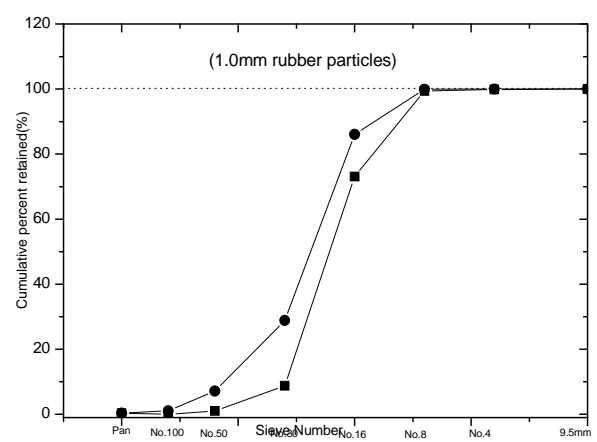

FIGURE I. GRADATION CURVES RUBBER PARTICLES

\section{B. Mixtures}

A typical mortar mix proportion with the ratio of sand to cement of about 3:1 by volume, was used for the tire-rubber particle cement mortar (TRPCM). The mix design was varied in terms of the percentages of tire-rubber particles as a replacement of sand by volume. A control mortar mixture was designed without rubber particles, and the five mortar mixtures 
were designed with the rubber particle contents of $5,10,15$, 20 and $25 \%$ as replacement of sand by volume, respectively. For an example of TRPCM $10 \mathrm{mix}$, rubber particles replaced $10 \%$ of sand by volume. For each mixture, cement and sand were first mixed for 1 minute and then the tire-rubber particles were added while mixing. Approximately half of the water needed was added and mixed for 2 minutes. The remaining water was then added and mixed until uniform mixture was obtained. All specimens were consolidated using rod and were kept damp inside the molds for 24 hours, after which they were cured in a water tank until being tested. Table I. gives the details of the mix design used TRPCM in the present work.

TABLE I. MIXTURES OF RPCM USED IN THIS STUDY

\begin{tabular}{ccccc}
\hline Mix No. & $\begin{array}{c}\text { Cement } \\
\left(\mathrm{kg} / \mathrm{m}^{3}\right)\end{array}$ & $\begin{array}{c}\text { Water } \\
\left(\mathrm{kg} / \mathrm{m}^{3}\right)\end{array}$ & $\begin{array}{c}\text { Sand } \\
\left(\mathrm{kg} / \mathrm{m}^{3}\right)\end{array}$ & $\begin{array}{c}\text { Rubber } \\
\text { particle } \\
\left(\mathrm{kg} / \mathrm{m}^{3}\right)\end{array}$ \\
\hline TRPCM 0 & 526 & 263 & 1230 & 0 \\
\hline TRPCM 5 & 526 & 263 & 1168 & $21(5 \%)$ \\
\hline TRPCM 10 & 526 & 263 & 1107 & $42(10 \%)$ \\
\hline TRPCM 15 & 526 & 263 & 1045 & $63(15 \%)$ \\
\hline TRPCM 20 & 526 & 263 & 984 & $84(20 \%)$ \\
\hline TRPCM 25 & 526 & 263 & 923 & $105(25 \%)$ \\
\hline
\end{tabular}

\section{Test Procedures}

To evaluate the effect of waste tire-rubber particles on mechanical properties of TRPCM, compressive tests were conducted for hardened TRPCM using the cube specimen of $50 \times 50 \times 50 \mathrm{~mm}$ according to KS F 2405 which is very similar with ASTM C39. The flexure tests were conducted for the hardened TRPCM using 40 x 40 x $160 \mathrm{~mm}$ beam specimen according to KS F 2407 which is very similar with ASTM C78. The compressive and flexural tests in this study are shown in Fig. II, respectively. Compressive and flexural tests were performed by a universal testing machine and a sensitive data acquisition system. Loading rate was chosen to be 0.005 $\mathrm{mm} / \mathrm{sec}$ and $0.001 \mathrm{~mm} / \mathrm{sec}$ for compressive and flexural tests, respectively. Compressive and flexure strengths were evaluated at the ages of 7,14 and 28 days.

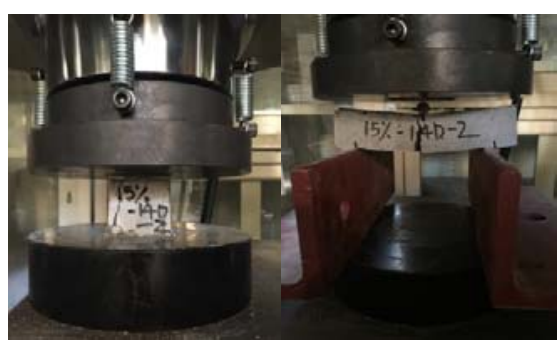

FIGURE II. SETUP FOR COMPRESSIVE AND FLEXURAL TESTS

\section{EXPERIMENTAL RESULTS AND DISCUSSION}

\section{A. Compressive Strength}

The average compressive strengths of TRPCM at 7,14 and 28 days are given in Table II. As described in many research studies, for a relatively higher volumes of replacement of aggregates with rubber $[4,6,11]$, the compressive strength of rubberized concrete indicated a significant reduction with the increase in rubber content compared to plain concrete. In this study, the obtained compressive strength of TRPCM showed similar results with significant reduction for specimens with $10,15,20$ and $25 \%$ replacement of rubber particle content. The reduction values of TRPCM for 10, 15, 20 and 25\% replacement of rubber particle are about 16.95, 39.00, 48.55 and $42.51 \%$ at 28 days as compared to that of the plain mortar, respectively. However, it was observed that the specimen with $5 \%$ replacement of rubber particle showed a marginal increase of compressive strength as compared to the plain mortar, approximately $10.17,8.05$ and $7.30 \%$ at 7, 14 and 28days, respectively. It can be noted, that for the specimens with $5 \%$ replacement of sand by rubber particles, a relatively smaller content or size of rubber particles in mortar would result in higher compressive strength due to a marginal filling effect between tire-rubber particles and cement matrix. Also there was no significant increase in compressive strength for the specimens tested 7days to 28days with the rubber particle replacement content between the $15 \%$ and $25 \%$. Therefore, further intensive research is required to verify the results presented in this work.

TABLE II. COMPRESSIVE STRENGTHS FOR TRPCM

\begin{tabular}{ccccc}
\hline Mix No. & $\begin{array}{c}\text { Rubber } \\
\text { Content } \\
(\%)\end{array}$ & $\mathbf{7}$ days (MPa) & 14 days (MPa) & 28 days (MPa) \\
\hline TRPCM 0 & $0 \%$ & $14.35( \pm 0.55)$ & $24.73( \pm 3.14)$ & $26.84( \pm 2.15)$ \\
\hline TRPCM 5 & $5 \%$ & $15.81( \pm 1.72)$ & $26.72( \pm 0.90)$ & $28.80( \pm 1.89)$ \\
\hline TRPCM 10 & $10 \%$ & $12.60( \pm 2.12)$ & $18.09( \pm 1.22)$ & $22.29( \pm 1.58)$ \\
\hline TRPCM 15 & $15 \%$ & $14.51( \pm 1.07)$ & $16.85( \pm 1.37)$ & $16.37( \pm 1.28)$ \\
\hline TRPCM 20 & $20 \%$ & $12.45( \pm 0.76)$ & $10.82( \pm 0.59)$ & $13.81( \pm 0.39)$ \\
\hline TRPCM 25 & $25 \%$ & $9.67( \pm 3.63)$ & $13.81( \pm 1.34)$ & $15.43( \pm 1.20)$ \\
\hline
\end{tabular}

The typical stress-strain curves at 28days for compression test are shown in Fig. III. As demonstrated in Fig. III, the addition of tire-rubber particles to mortar does not seem to increase the compressive strength as compared to that of plain mortar. However, strain values corresponding to the peak load mostly increased with the increase in rubber-particle content. The modulus of elasticity of the TRPCM decreased significantly with the increase of rubber-particle content for 10 15,20 and $25 \%$ of rubber replacement, respectively. Similar results were also found in concretes contained scrap-tirerubber particles [10]. Unlike other results of research, it was found that $5 \%$ of replacement of rubber-particle in cement mortar showed higher elastic modulus than that of plain mortar.

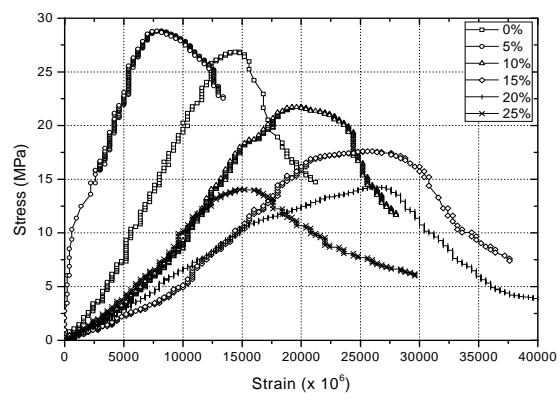

FIGURE III. STRESS-STRAIN CURVES OF TRPCM UNDER COMPRESSION TEST 


\section{B. Flexure Strength}

Flexural tests were conducted for rectangular beam specimen of $40 \times 40 \times 160 \mathrm{~mm}$ under a load in a three-point bending test. The average flexural strengths for the specimens of 7, 14 and 28 days are given in Table III. Specimen with 5 and $10 \%$ replacement with rubber showed higher value of flexural strength than the control specimen at 7days, while the specimen with $5 \%$ replacement of sand with rubber particle only showed higher of flexural strength at 14days, Whereas 5, 10 and $15 \%$ replacements showed higher flexural strength than plain mortar at 28days. A smaller reduction in flexural strength was observed in the specimen at 28 days with the rubber particle contents of 20 and $25 \%$. These results were similar to that found in the study of concrete containing rubber chips by Toutanji [1]. Such results may have been due to the reduction of binder content in the mortar mixture or due to small size of rubber particle in the mortar mixtures.

TABLE III. FLEXURE STRENGTHS FOR TRPCM

\begin{tabular}{ccccc}
\hline Mix No. & $\begin{array}{c}\text { Rubber } \\
\text { Content } \\
(\%)\end{array}$ & $\begin{array}{c}7 \text { days } \\
(\mathrm{MPa})\end{array}$ & $\begin{array}{c}\mathbf{1 4} \text { days } \\
(\mathrm{MPa})\end{array}$ & $\begin{array}{c}\mathbf{2 8} \text { days } \\
(\mathrm{MPa})\end{array}$ \\
\hline TRPCM 0 & $0 \%$ & $4.92( \pm 0)$ & $6.17( \pm 0.23)$ & $7.12( \pm 0.55)$ \\
\hline TRPCM 5 & $5 \%$ & $5.43( \pm 1.01)$ & $6.78( \pm 0.19)$ & $8.25( \pm 0.77)$ \\
\hline TRPCM 10 & $10 \%$ & $5.17( \pm 0.25)$ & $5.58( \pm 0.57)$ & $7.20( \pm 0.58)$ \\
\hline TRPCM 15 & $15 \%$ & $4.58( \pm 0.50)$ & $5.64( \pm 0.67)$ & $8.04( \pm 0.91)$ \\
\hline TRPCM 20 & $20 \%$ & $4.32( \pm 1.67)$ & $5.36( \pm 0.99)$ & $5.57( \pm 0.67)$ \\
\hline TRPCM 25 & $25 \%$ & $4.44( \pm 1.61)$ & $5.44( \pm 0.87)$ & $6.69( \pm 1.09)$ \\
\hline
\end{tabular}

Load-deflection curves for TRPCM under flexural tests are shown in Fig. VI. Toughness, defined as the area under loaddeflection curve of a flexural test, for TRPCM was higher than that for plain mortar approximately as much as $50 \%$.

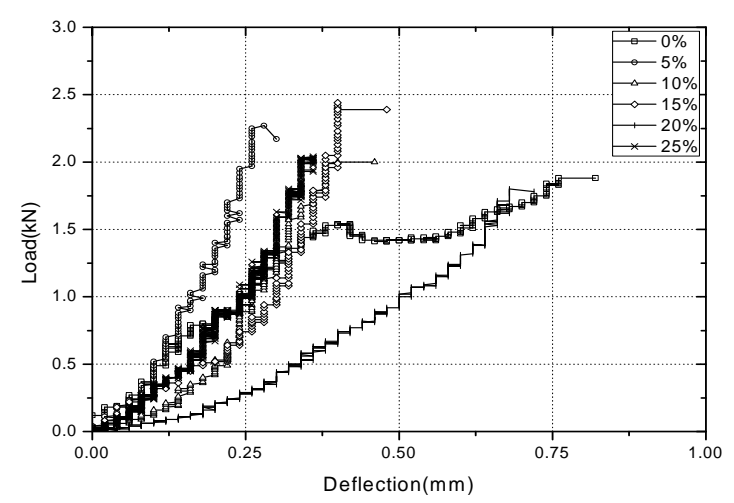

FIGURE VI. LOAD-DEFLECTION CURVES OF TRPCM UNDER FLEXURAL TEST

\section{CONCLUSIONS}

This study investigated the effect of small size waste tirerubber particles in cement mortar (TRPCM) with the average size of $1.0 \mathrm{~mm}$. Based on the study, the following conclusions are drawn:
1. It was observed that the $5 \%$ replacement of rubber particle showed a marginal increasing of compressive strength as compared to the plain mortar by approximately 10.17, 8.05 and $7.30 \%$ at 7,14 and 28days, respectively. It can be noted that a relatively smaller content or size of rubber particles in cement mortar resulting in higher compressive strength may due to a marginal filling effect between tire-rubber particles and cement matrix.

2. The addition of tire-rubber particles to cement mortar does not seem to increase the compressive strength as compared to that of plain mortar. However, strains corresponding to the peak load mostly increased with the increase in rubber-particle content.

\section{ACKNOWLEDGMENT}

The work presented in this paper was funded by National Research Foundation of Korea (NRF2014R1A2A2A01004164) under the Ministry of Ministry of Science, ICT and Future Planning.

\section{REFERENCES}

[1] Toutanji, H. A., The use of rubber tire particles in concrete to replace mineral aggregates, cement and Concrete Composite, Vol.18, pp.135139, 1996.

[2] ] Eldin, N. N. and Senouci, A.B., Measurement and prediction of the strength of rubberized concrete, Cement Concrete Composite, Vol.16, pp. 287-9 298, 1994.

[3] Boudaoud Zeineddine and Beddar Miloud, Effects of recycled tires rubber aggregates on the characteristics of cement concrete, Open Journal of Civil Engineering, Vol. 2, pp. 193-197, 2012.

[4] Albano, C., Camacho, N., Reyes, J., Feliu, J. l. and Hernandez, M., Influence of scrap rubber addition to Portland I concrete composites: Destructive and non-destructive testing, Composite Structures, Vol. 71, pp. 439-446, 2005.

[5] Segre, N. and Joekes, I., Use for tire rubber particles as addition to cement paste, Cement Concrete Research, Vol. 30 (9), pp. 1421-1425, 2000.

[6] Siddiquel, R. and Naik, T. R., Properties of concrete containing scrap tire rubber -an overview. Waste Management, Vol.24, pp. 563-569, 2004.

[7] Guneyisi Erhan, Gesoglu Mehmet and Ozturan Turan, Properties of rubberized concretes containing silica fume, Cement and Concrete Research, Vol. 34, pp. 2309-2317, 2004.

[8] Hernandez-Olivares, F., Barluenga, G., Bollati, M., Witoszek, B., Static and dynamic behavior of recycled tire rubber-filled concrete. Cement and Concrete Research, Vol. 32, pp. 1587-596, 2002.

[9] Li Guoqiang, Garrick Gregory, Eggers John, Abadie Christopher, Michael A. Stubblefield and Pang Su-Seng, Waste tire fiber modified concrete, Composites: Part B: Engineering, Vol.35, pp. 305-312, 2004.

[10] Ganjian Eshmaiel, Khorami Morteza and Maghsoudi Ali Akbar, Scraptyre-rubber replacement for aggregate and filler in concrete, Construction and Building materials, Vol. 23, pp. 1828-1836, 2009.

[11] Yilmaz Arin and Degirmenci Nurhayat, Possibility of using waste tire rubber and fly ash with Portland cement as construction materials, Waste Management, Vol.29, pp. 1541-1546, 2009.

[12] Aiello, M.A. and Leuzzi, F., Waste tyre rubberized concrete: properties at fresh and hardened state, Vol. 30, pp. 1696-1704, 2010.

[13] Zheng, L., Sharon , X. and Yuan, Y., Experimental investigation on dynamic properties of rubberized concrete, Construction and Building Materials, Vol.22, pp. 939-947, 2008.

[14] Choi , Y. and Yuan, R. L., Experimental relationship between splitting tensile strength and compressive strength of GFRC and PFRC, Cement and Concrete Research, Vol. 35, pp. 1587-1591,20 